\title{
Lipomatous myelomeningocele, athyrotic hypothyroidism, and sensorineural deafness: a new form of syndromal deafness?
}

\author{
H L Peters, A Bankier
}

\begin{abstract}
This case report describes a 4 year old boy with the unique triad of lipomatous myelomeningocele, congenital hypothyroidism secondary to thyroid agenesis, and sensorineural deafness. While associations between deafness and abnormal thyroid function and deafness and sacral lipoma have previously been described, the constellation of findings in this patient has not been reported.

$(\mathfrak{F}$ Med Genet 1998;35:948-950)
\end{abstract}

Keywords: lipomatous myelomeningocele; hypothyroidism; sensorineural deafness

\section{Case report}

The proband was the first child of nonconsanguineous parents aged 33 and 34 years. The pregnancy was uncomplicated and the infant was delivered at term. Initial examination showed a healthy infant with a minor degree of cranial sutural separation and a slightly enlarged anterior and posterior fontanelle. A soft mobile lump was noted over the lateral border of the right sacral region. The remainder of the spine appeared normal. Lower limb structure, neurological function, anal tone, and urinary function were normal.

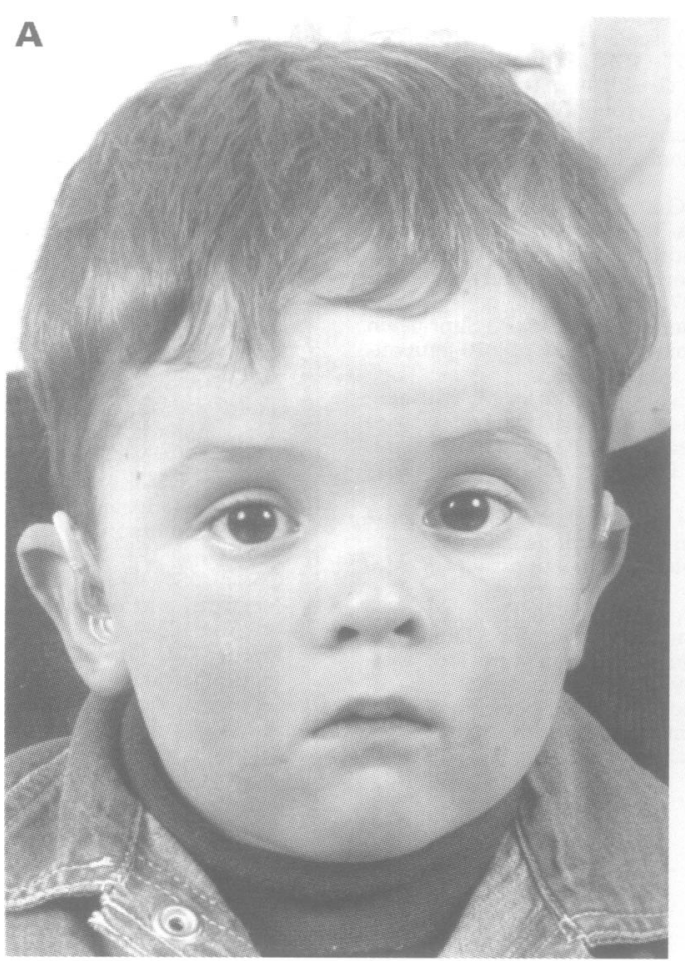

Figure 1 The proband showing telecanthus and low set ears (A) front view and (B) profile. (Photographs reproduced with permission.)

On day 2 the infant developed unconjugate $\underset{\$}{\overparen{2}}$ hyperbilirubinaemia. The maximum bilirubie was $286 \mu \mathrm{mol} / 1$. The infant required 48 hours of phototherapy.

\section{LIPOMATOUS MYELOMENINGOCELE}

The sacral lump noted at birth was shown to be्户 a lipomatous myelomeningocele by ultrasoun and magnetic resonance imaging. It was surgi $i=$ cally removed at 7 months of age. The tumour was a large lumbosacral lipoma with extra- anç intraspinal involvement. It was associated with intrathecal tethering and a significant degree of intraspinal involvement with extensive adhe sions to structures in the terminal cordo Despite this the child has had minimal neuro $\frac{\mathbb{}}{3}$ logical impairment of his lower limbs. He walk with an intoed gait and has minimal increase in tone in his right leg with brisker reflexes.

\section{HYPOTHYROIDISM}

The diagnosis of hypothyroidism was made or a positive Guthrie screening test and was con firmed with free T4 and TSH levels (T4<5y $\mathrm{pmol} / \mathrm{l}, \mathrm{TSH}>700 \mathrm{mU} / \mathrm{l})$. A thyroid technetium scan showed absence of the thyroid gland and the diagnosis of athyrotic hypothyroidism was made. The infant started thyroxine on days 11 of life. Since this time his free T4 and TSFE

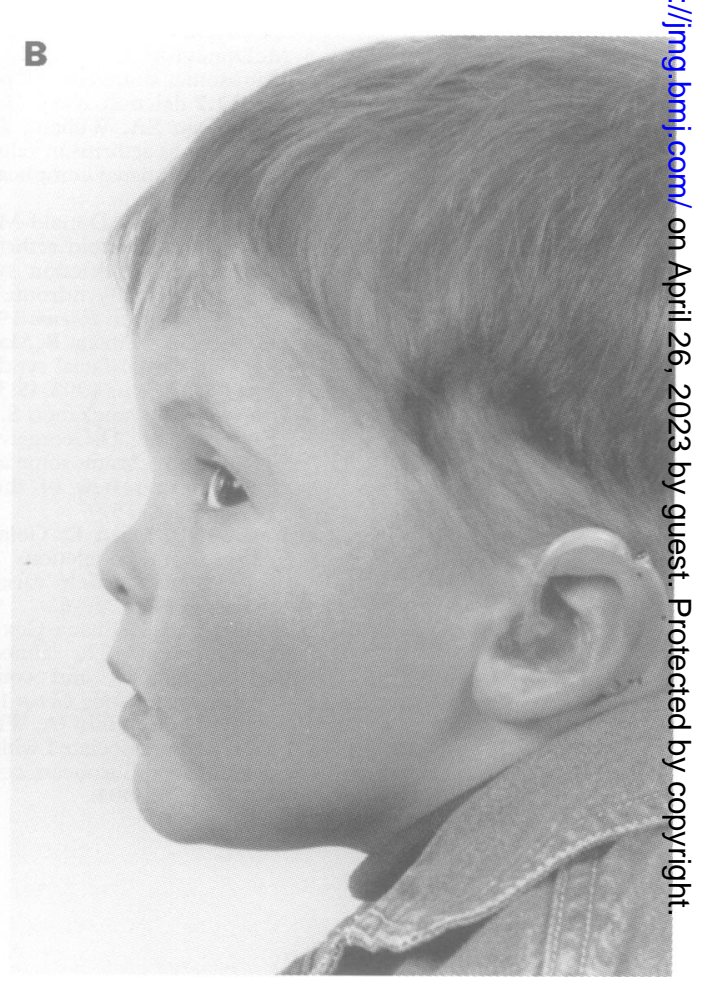

Received 19 November 1997 Revised version accepted for publication 8 April 1998

\author{
Victorian Clinical \\ Royal Children's \\ Hospital, Flemington \\ Road, Parkville, \\ Melbourne, Victoria \\ L L Peters \\ Correspondence to: \\ Dr Peters.
}


levels have remained normal on a daily dose of $75 \mu \mathrm{g}$ thyroxine. His physical and mental development have been reviewed on a regular basis and he has attained all appropriate milestones. Specifically, his linear growth has been normal.

SENSORINEURAL DEAFNESS

At 9 months of age his parents felt that he was not responding normally to sound. Audiometry confirmed a mild sensorineural hearing loss in the middle frequencies bilaterally. Investigations (including a CT scan of the inner ear, ENT and ophthalmological assessment, and TORCH titres) failed to find a cause for the deafness. There was no family history of deafness. Over the next 12 months his hearing deteriorated with loss of high frequency acuity and a right and left hearing threshold of $50 \mathrm{db}$. Speech assessment at 20 months of age suggested a two to three month delay. He was fitted with hearing aids and has subsequently made good progress with speech development.

In summary, this report describes a child (fig 1) with lipomatous myelomeningocele, athyrotic hypothyroidism, and sensorineural deafness. There is no relevant family history.

\section{Discussion}

Isolated congenital athyrotic hypothyroidism has an incidence of 1 in 5526. ${ }^{1}$ Although published reports suggest that there is familial aggregation of this disorder, patients with congenital athyrotic hypothyroidism appear to be a heterogeneous group. ${ }^{2}$ Sensorineural deafness has an incidence of 1 in $1000 .^{3}$ It has been associated with a multitude of other abnormalities and these make up the "syndromic congenital deafness" group. Lipomatous myelomenigocole is considered a form of spinal dysraphism and is rare.

A number of syndromes associate sensorineural deafness with abnormal thyroid dysfunction but not previously with congenitally absent thyroid gland. The most frequently reported of these syndromes is Pendred syndrome. This is thought to account for up to $7 \%$ of all cases of congenital deafness. ${ }^{4}$ Pendred syndrome results from an organification defect of the thyroid with the development of hypothyroidism in as many as $50 \%$ of cases in one study. ${ }^{4}$ The deafness associated with Pendred syndrome appears to be congenital in origin and in a number of cases is the result of a Mondini malformation. The second most common syndrome associating sensorineural deafness and hypothyroidism is JohansenBlizzard syndrome. The aetiology of the hypothyroidism in this syndrome is thought to be of pituitary origin. ${ }^{5}$ These patients also have a characteristic facial appearance (hypoplasia of the nasal alae), moderate to mild mental retardation, pancreatic insufficiency, and growth failure. The patient described in this report has none of these phenotypic features.

Recent reports support an association between non-syndromal congenital hypothyroidism and deafness. ${ }^{6-8}$ These reports suggest that up to $20 \%$ of children with congenital hypothyroidism have some degree of hearing impairment, usually sensorineural with loss in the high frequencies. The cause of this association may be because of delay in thyroxine therapy in the newborn period. For example, Rovet et al reported a positive association between delay in thyroxine treatment (up to three weeks) and development of hearing impairment in a cohort of 101 newborns. Although the thyroid gland and cochlea are both of ectodermal origin and hence the association is not altogether surprising, the exact pathophysiology leading to the hearing loss is unclear. Animal studies have shown that offspring of mothers rendered hypothyroid by thyroid antagonists have immature development of the organ of Corti and hair cells. ${ }^{7910}$ Pathological examination of the cochlea of a homozygous mouse model for congenital hypothyroidism showed an abnormality in the stereocilia of the inner and outer hair cells. ${ }^{11}$ Although the child described in this case report was promptly diagnosed and treated for hypothyroidism, it may be that such mechanisms explain the association in this child of sensorineural deafness and hypothyroidism.

There are a number of well recognised associations between hypothyroidism and neurological abnormalities. For example, Jung et $a l^{12}$ described two children with anterior chamber cleavage disorder, cerebellar hypoplasia, hypothyroidism, and tracheal stenosis. Three unrelated patients have been described with ectodermal dysplasia, hypothyroidism, and agenesis of the corpus callosum. ${ }^{13}$ In terms of specific spinal abnormalities, two cases of sacral lipoma and sensorineural deafness have been described. ${ }^{14}{ }^{15}$ Two of these cases were sibs, both of whom also had cleft lip and palate. One of the brothers also had extra digital appendages, while the other child had a rotation defect of the penis, anterior meningocele, and dislocated hip. Gorlin refers to a third case with similar features to the above described sibs. ${ }^{15}$ Van Langen and Hennekam ${ }^{16}$ described a child with a variety of abnormalities, including an aberrant "digit-like" appendage, sensorineural deafness, and large sacral dimple. The authors suggested that this constellation of clinical findings represented a human homologue for the mouse mutant disorganisation. ${ }^{14-16}$ The mouse mutant disorganisation describes a dominant gene that potentially results in a range of malformations affecting multiple organs. The striking features of this condition are the limb abnormalities, with reduction or duplication and limbs/digits arising from abnormal sites. ${ }^{17}$ The patient described in this report does not have limb defects or the characteristic hamartomas to suggest this syndrome.

In conclusion, there are a number of known associations between the combinations (1) congenital hypothyroidism and sensorineural deafness, (2) congenital hypothyroidism and structural neurological abnormalities, and (3) sacral lipoma and sensorineural deafness. Several plausible pathophysiological explanations have been given for these associations based on animal models. To date, however, the unique triad of lipomatous myelomeningocele, 
congenital hypothyroidism secondary to thyroid agenesis, and sensorineural deafness has not been reported. Whether this constitutes a distinct syndrome will only be clarified by further reports.

1 Brown AL, Fernhoff PM, Milner J, McEwen C, Elsas LS. Racial differences in the incidence of congenital hypothyroidism. F Pediatr 1981;99:934-6.

2 McKusick VA. Mendelian inheritance in man. A catalog of human genes and genetic disorders. 11 th ed. Baltimore: Johns Hopkins University Press, 1994:218700.

3 Schein JD. Childhood hearing loss: epidemiology and implications. Birth Defects 1980;16:3-7.

4 Reardon W, Trembath RC. Pendred syndrome. 7 Med Genet 1996;33:1037-40.

5 Hurst JA, Baraitser M. Johanson-Blizzard syndrome. $\mathcal{F ~ M e d ~}$ Genet 1989;26:45-8.

6 Rovet J, Walker W, Bliss B, Buchanan L, Ehrlich R. Long term sequelae of hearing impairment in congenital hypothyroidism. F Pediatr 1996;128:776-82.

7 Vanderschueren-Lodeweyckx M, Debruyne F, Dooms L Eggermont E, Eeckels R. Sensorineural hearing loss in sporadic congenital hypothyroidism. Arch Dis Child 1983; 58:419-22.

8 Debruyne F, Vanderschueren-Lodeweyckx M, Bastijns $P$ Hearing in congenital hypothyroidism. Audiology 1983;22 404-9.
9 Kohonen A, Juhiainen T, Liewendahl K, Tarkkenen J, Kaimio $M$. Deafness in experimental hypo- and hyperthyroidism. Larymgoscope 1971;81:947-56.

10 Francois M, Bonfils P, Leger J, Avan P, Czernichow P, Narcyc P. Audiological assessment of eleven congenital hypothy- $\bar{Z}$ roid infants before and after treatment. Acta Otolaryngol $\mathbb{D}$ 1993;113:39-42

11 O'Malley BW Jr, Li D, Turner DS. Hearing loss and cochlear abnormalities in the congenital hypothyroid (hyt/hyt) mouse. Hearing Res 1995;88:181-9.

12 Jung $C$, Wolff G, Back E, Stahl M. Two unrelated children. with developmental delay, short stature and anterior chamber cleavage disorder, cerebellar hypoplasia, endocrine disturbance and tracheostenosis: a new entity? Clin Dysmor phol 1995;4:44-51.

13 Fryns JP, Chrzanowska K, Van Den Berghe H. Hypohid-O rotic ectodermal dysplasia, primary hypothyroidism, and $\bar{s}$ agenesis of the corpus callosum. $\mathcal{F}$ Med Genet 1989;26:520-? 34.

14 Lowry RB, Young S. Cleft lip and palate, sensorineural deafness, and sacral lipoma in two brothers: a possible example of the disorganisation mutant. $\mathcal{F}$ Med Genet 1991; $\overrightarrow{0}$ 28:135-7.

15 Gorlin RJ. Hereditary hearing loss and its syndromes. New York: Oxford University Press, 1995:424.

16 Van Langen IM, Hennekam RCM. Another example of theO human homologue of the mouse mutant disorganization? Clin Dysmorphol 1994;3:361-2.

17 Winter RM, Donnai D. A possible human homologue for the mouse mutant disorganisation. 7 Med Genet 1989;26: $\mathrm{W}$ 417-20. 